\title{
EDITORIAL: URI YECHIALI
}

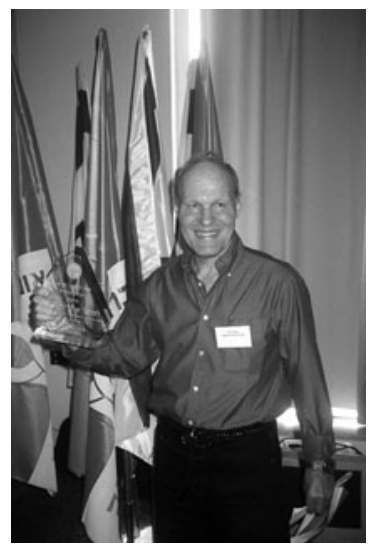

FIGURE 1. Uri Yechiali receiving the Life Achievement Prize from ORSIS, the Israeli Operation Research Association, May 2004.

A number of times over the last 15 years Uri Yechiali proposed to some of us to join forces and organize an international workshop on Networks/Queues/ Performance/Stochastic Modeling in Israel. Each time, the idea looked very attractive and promising, but somehow faded away-perhaps because each of us had to do something more urgent the next morning. In October 2005, when Uri told us about his upcoming retirement and raised the proposal again, we understood that "it's now or never" and accepted the challenge.

The workshop entitled "Networks, Queues, Performance, and Stochastic Modeling," celebrating Uri Yechiali's retirement, was held May 17-19, 2006, in Shefayim, Israel. Friends of Uri from around the globe - colleagues, co-authors, former professors and graduate students-took part in the workshop. Their contributions resulted in a rich and diverse scientific program, and their enthusiastic participation resulted in a highly energetic and jolly atmosphere.

Motivated by the workshop's great success, we decided to make an extra effort and publish a special issue of an international Applied Probability scientific journal, 
hosting papers contributed to the workshop. We were delighted when Sheldon Ross offered to devote a special issue of PEIS to this purpose.

This $P E I S$ special issue contains articles on a large variety of Applied Probability topics includings (1) polling systems, (2) multiserver queues, (3) queues with service interruptions, (4) queue fairness, (5) queues with impatient customers, (6) $G / G I / \infty$ queues, (7) traffic control via Markov decision processes, (8) Internet-related retrial networks, and (9) stochastic clustering.

This PEIS special issue hosts two articles co-authored by Uri and well reflects two key characteristics of his research: Diversity and Collaboration. Throughout his career, Uri found interest in a wide span of Applied Probability topics and tackled an abundance of Stochastic Modeling problems-always doing so with his unique zeal, originality, and creativity. Throughout his career, he collaborated extensively with an impressive body of researchers from around the globe, and he mentored a massive cadre of graduate students-making many of his co-authors and students also close friends.

He received B.Sc. in Industrial Engineering (1964) and M.Sc. in Operations Research (1966) from the Technion, Israel, and Ph.D. in Operations Research (1969) from Columbia University. After teaching for two years at NYU he joined the Department of Statistics and Operations Research of Tel Aviv University (1971). He chaired the Department twice (1981-1983 and 1996-1999) and retired from it in 2005. He served as the President of the Israeli OR Society (1983-1985) and was awarded the Society's "Life Achievement" prize in 2004. After his retirement, Uri joined the Afeka College of Engineering - to establish and chair their Department of Industrial Engineering.

We wholeheartedly thank both the contributors and the anonymous reviewers of this special issue. Special thanks go to Sheldon Ross and the PEIS team. Last (but not least), we wish to thank Uri Yechiali for "setting the stage" and initiating the workshop, congratulate Uri upon his retirement, and salute Uri for contradicting the sociological "entropy law" of retirement—continuously and consistently astonishing us by ever increasing activeness and vigorousness.

Eitan Altman

Iddo Eliazar

Hanoch Levy 